\title{
Cardiovascular Risk Factors in Patients with Acute MI in a Secondary Hospital in Bangladesh
}

\author{
Mohammad Ullah'1. Suman Kumar Saha ${ }^{2}$, Md Toufiqur Rahman ${ }^{3}$, \\ Md Abdul Karim ${ }^{3}$, Rashid Ahmed ${ }^{3}$ \\ ${ }^{1}$ Department of Cardiology, Sir Salimullah Medical College, Dhaka, ${ }^{2}$ Department of Cardiology, Dhaka \\ Medical College, Dhaka, ${ }^{3}$ Department of Cardiology, Col. Malek Medical College, Manikganj
}

\section{Key Words : Cardiovascular risk factor, $I H D$, Bangladesh, Manikganj.}

\begin{abstract}
:
Background: Incidence of noncommunicable disease, specially cardiovascular diseases, is increasing in Bangladesh. Prevalence of risk factors in ischaemic heart disease (IHD) has been studied in different tertiary hospitals and institutes. This study was done in a secondary hospital with a patient population mainly of low socioeconomic condition and was compared with other patient groups of the country and Indian subcontinent.
\end{abstract}

Methods: this cross sectional study was conducted in Manikganj Sadar Hospital from July 2019 to December 2019. All the patients admitted with the diagnosis of myocardial infarction (MI) were included. Cardiovascular risk factors, like smoking, diabetes mellitus (DM), hypertension (HTN), family history of premature cardiovascular diseases, dyslipidaemia and obesity, were evaluated among the patients.

Results: This cross-sectional study showed most of the patients were in the age group of 50-59 years. $66 \%$ of the male patients and $2 \%$ of the female patients were smoker. $66 \%$ of the patients were hypertensive, $44 \%$ patients were diabetic, $28.5 \%$ patients were overweight, $60.4 \%$ patients had total cholesterol $>200 \mathrm{mg} / \mathrm{dl}, 73.6 \%$ patients had $\mathrm{LDL}>130 \mathrm{mg} / \mathrm{dl}, 11076.3 \%$ patients had $H D L<40 \mathrm{mg} /$ $\mathrm{dl}, 72.2 \%$ had triglyceride $>150 \mathrm{mg} / \mathrm{dl}$ and $39 \%$ patients had family history of premature cardiovascular disease. Ninety (62.5\%) patients had anterior MI, 50 (34.7\%) patients had inferior MI and $4(2.7 \%)$ patients had NSTEMI. 65 patients had no major risk factor and $57 \%$ had three or more risk factors.

Conclusion: The study population was more aged in comparison to other studies conducted in different parts of Bangladesh. Prevalence of smoking habit was lower but the prevalence of HTN, $D M$ and dyslipidaemia were higher than the general population and other cohorts of MI patients. The prevalence of major risk factors was much higher than the general population of Bangladesh.

(Cardiovasc. j. 2020; 12(2): 96-101)

\section{Introduction:}

Noncommunicable diseases (NCD) are rapidly becoming a major public health threat in the developing countries like Bangladesh. These diseases constituted $43 \%$ of the global burden of disease in 1999. Based on current trends, by 2020 they will account for $73 \%$ of deaths and $60 \%$ of the disease burden in the developing countries. ${ }^{1}$ Like many other countries, Bangladesh has been experiencing an epidemiological transition from communicable disease to NCDs. ${ }^{2}$ Among the NCDs, cardiovascular diseases (CVD) is the most prevalent one. South Asians including Bangladeshi patients have been found to have a higher proportional mortality rate from ischemic heart disease compared with other Asian ethnic groups

Address of correspondence: Dr. Mohammad Ullah, Department of Cardiology, Sir Salimullah Medical College, Dhaka, Bangladesh. Email- firoze1970@gmail.com

- 2020 authors; licensed and published by International Society of Cardiovascular Ultrasound, Bangladesh Chapter and Bangladesh Society of Geriatric Cardiology. This is an Open Access article distributed under the terms of the CC BY NC 4.0 (https://creativecommons.org/licenses/by-nc/4.0). 
and non-Hispanic whites. ${ }^{3}$ Bangladeshi population suffer from MI 5-10 years earlier than the western population. ${ }^{4}$ And this young population has got a different risk factor profile. ${ }^{5}$ in a study conducted in Rajshahi in 2005, it was found that $57 \%$ patients are smoker, $45 \%$ patients are diabetic and $46 \%$ patients has got raised LDL level. ${ }^{6}$ These data differ with the BRAVE study conducted in National Institute of Cardiovascular Diseases, Dhaka. BRAVE study included 4900 patients, $53 \%$ of them from rural areas and $47 \%$ from the urban areas. ${ }^{7}$ Data of cardiovascular risk factors also differ with the STEPS study, which is a cross sectional study, using stratified sampling method, a national survey conducted in Bangladesh in 2010. ${ }^{8}$ Manikganj Sadar Hospital id situated in a district town near capital city Dhaka. Mainly people with low socioeconomic condition take service from the inpatient department of the hospital. So, prevalence of cardiovascular risk factors in AMI patients attending in this hospital will give us updated information about the risk factors off this community and will help to formulate the strategy of primary prevention of cardiovascular diseases among the people from rural areas with low socioeconomic condition.

\section{Methods:}

The cross-sectional study was conducted in Manikganj Sadar Hospital, a secondary level hospital of Manikganj district, about sixty kilometers from Dhaka. Patients from low and lower middle class of socioeconomic condition form the main bulk of inpatient department of this hospital. All the patients who were admitted with first attack of MI from April 2019 to July 2019 were included in the study. Myocardial infarction was defined by history of chest pain, ECG changes and raised Troponin I level. Patients were classified in anterior MI, Inferior MI and NSTEMI, depending on the ECG criteria. History, physical examination and investigations were done to evaluate the cardiovascular risk factors. Smoking was defined if the patient was current, recent or past smoker. Hypertension was defined if the patients' systolic blood pressure was e" 140 $\mathrm{mmHg}$ or diastolic blood pressure e" $80 \mathrm{~mm} \mathrm{Hg}$ or the patient was taking anti-hypertensive drugs. Diabetes mellitus was defined as per the ADA criteria. ${ }^{9}$ Family history was defined as per ACC/ AHA criteria. ${ }^{10} \mathrm{BMI}>24.9-29 \mathrm{~kg} / \mathrm{m}^{2}$ was defined as overweight and $\geq 29 \mathrm{~kg} / \mathrm{m}^{2}$ was defined as obese. Serum total cholesterol $>200 \mathrm{mg} / \mathrm{dl}, \mathrm{LDL}>130$ $\mathrm{mg} / \mathrm{dl}$, triglyceride $>150 \mathrm{mg} / \mathrm{dl}$ and $\mathrm{HDL}<40 \mathrm{mg} /$ dl was defined as abnormal and abnormality of any of these values or history of taking anti lipid drugs was defined as dyslipidaemia. Serum creatinine level $>1.4 \mathrm{mg} / \mathrm{dl}$ was termed a renal failure and rheumatoid arthritis was diagnosed form history and clinical features. Informed written consent of the patients was taken before inclusion in the study. Prevalence of different risk factors were analyzed and was compared with the values in general population.

\section{Results:}

The cross-sectional study was done to find out the prevalence of different cardiovascular risk factors among the patients with first attack of MI in a secondary level hospital. 144 patients were included in the study. $102(70.8 \%)$ of them were male and $42(29.2 \%)$ were female (male: female 2.4:1). Age range of the patients is 40-100 years (mean age $58.5 \pm 13.2$ years). Most of the patients are in the range of $50-59$ years (34.7\%). Most of the patients had at least one of the major risk factors. Sixty-seven (46\%) patients were smoker and they used to smoke on average 13 cigarettes/ day. Ninety-five (66\%) patients were hypertensive and $69(69.5 \%)$ of them used to take some form anti-hypertensive drugs with or without optimal control of blood pressure. Forty-one (28.5\%) patients were overweight and rest of the patients were of normal BMI and none of the patients were obese. Prevalence of DM was 64 (44.5\%). Thirtysix of them were taking metformin, 02 of them were taking insulin and 23 of them were taking other oral hypoglycaemic agents. Fifty-six (39\%) patients had history of premature cardiovascular disease in at least one of their first-degree relatives. Most of the patients were of normal BMI, only $41(28.5 \%)$ patients were overweight. No patient was obese. 


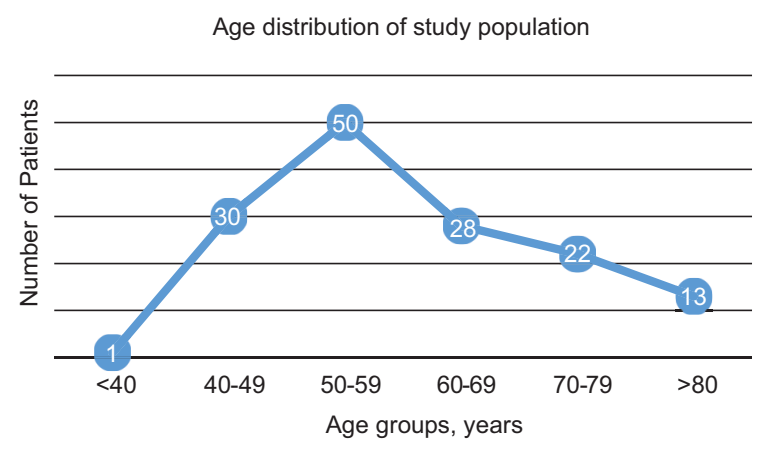

Fig.-1: Age distribution of study population $(n=144)$.

Table-I

Prevalence of major cardiovascular risk factors among the study population ( $N=144)$.

\begin{tabular}{lcc}
\hline Risk factors & Numbers & Percentage \\
\hline HTN & 95 & 66.0 \\
DM & 64 & 44.5 \\
Smoking & 67 & 46.0 \\
Total cholesterol $>200 \mathrm{mg} / \mathrm{dl}$ & 87 & 60.4 \\
HDL < $40 \mathrm{mg} / \mathrm{dl}$ & 110 & 76.3 \\
LDL> $130 \mathrm{mg} / \mathrm{dl}$ & 106 & 73.6 \\
TG $>150 \mathrm{mg} / \mathrm{dl}$ & 104 & 72.2 \\
Family history of premature CVD & 56 & 39.0 \\
Renal failure & 25 & 17.4 \\
Overweight & 41 & 28.5 \\
\hline
\end{tabular}

Eighty-seven (60.4\%) patients had total cholesterol $>200 \mathrm{mg} / \mathrm{dl}, 106$ (73.6\%) patients had LDL>130 mg/ dl, 110 (76.3\%) patients had HDL < $40 \mathrm{mg} / \mathrm{dl}$ and $104(72.2 \%)$ had triglyceride $>150 \mathrm{mg} / \mathrm{dl}$.

Ninety (62.5\%) patients had anterior MI, 50 (34.7\%) patients had inferior MI and $4(2.7 \%)$ patients had NSTEMI. Prevalence HTN was significantly higher in inferior MI patients on the other hand, prevalence of family history of premature cardiovascular diseases and dyslipidaemia were significantly higher in anterior MI patients. There was no significant difference regarding the prevalence of smoking, DM, overweight and renal failure.

Two patients had all the major risk factors (smoking, HTN, family history of premature cardiovascular disease, overweight and dyslipidaemia). 15 patients had at least one of the risk factors, 38 patients had at least two, 50 patients had at least three, 25 patients had at least four, 05 patients had at least five and 9 patients had no risk factors.

Table-II

cardiovascular risk factors in different types of $M I(N=144)$.

\begin{tabular}{|c|c|c|c|c|}
\hline Risk factors & Anterior MI (n=90) & Inferior MI $(n=50)$ & NSTEMI (n=04) & $\mathrm{p}$ value \\
\hline Smoking & $45(50 \%)$ & $21(42 \%)$ & $01(25 \%)$ & 0.36 \\
\hline $\mathrm{DM}$ & $59(41 \%)$ & $04(2.8 \%)$ & $01(25 \%)$ & 0.33 \\
\hline HTN & $47(52 \%)$ & $47(94 \%)$ & $01(25 \%)$ & $<0.05$ \\
\hline Family history & $40(44.4 \%)$ & $14(28 \%)$ & $02(50 \%)$ & $<0.05$ \\
\hline Overweight (BMI>24.9) & $29(20.1 \%)$ & $11(22 \%)$ & $01(25 \%)$ & 0.19 \\
\hline Renal failure & $17(18.9 \%)$ & $08(16 \%)$ & $0(0 \%)$ & 0.66 \\
\hline Total cholesterol $>200 \mathrm{mg} / \mathrm{dl}$ & $71(78.8 \%)$ & $16(32 \%)$ & $01(25 \%)$ & $<0.05$ \\
\hline $\mathrm{HDL}<40 \mathrm{mg} / \mathrm{dl}$ & $82(91 \%)$ & $26(52 \%)$ & $02(50 \%)$ & $<0.05$ \\
\hline $\mathrm{LDL}>130 \mathrm{mg} / \mathrm{dl}$ & $77(85.5 \%)$ & $27(54 \%)$ & $02(50 \%)$ & $<0.05$ \\
\hline Triglyceride $>150 \mathrm{mg}$ & $78(86.7 \%)$ & $24(48 \%)$ & $02(50 \%)$ & $<0.05$ \\
\hline
\end{tabular}

$\mathrm{p}$ value was calculated by chi-square test between anterior MI and inferior MI. 


\section{Discussion:}

This study was done to evaluate the risk factor profile of the patients who presented with myocardial infarction for the first time and got admitted in the hospital. Female patients were $29.2 \%$ of the study population, which is different than that of other studies conducted in Dhaka city (4-12\%). ${ }^{6,7,11}$ this difference may be due to increased incidence of MI in this group of people or due to referral of male members to the centers with advanced cardiac care in Dhaka, which is $60 \mathrm{Km}$ apart from Manikganj. Most of the patients (34.7\%) were of 50 to 59 years age group. This differs with results of BRAVE study conducted in National Institute of Cardiovascular Diseases, where 46\% patients were below the age of $50 .{ }^{7}$ But our findings are similar to that of the study conducted in Rajshahi, a divisional city of Bangladesh. ${ }^{6}$ Forty six percent patients were smoker. Smoking was more prevalent in male patients ( $66 \%$ vs. $02 \%$ ). This was much lower than that of other studies (around $80 \%) .6,7,11-14$ Inclusion of more female patients in our study population. Our findings are consistent with the study conducted in the same institution among the hypertensive patients. ${ }^{16}$ This high prevalence of smoking habit is also present among the general population of the country. About 55\% of adult males of the country are affected by this habit. About one third of the smokers start smoking before the age of $15 .{ }^{8}$ Lack of awareness and easy availability (cheap, available in every public place and available even as a single cigarette) is mostly responsible for this. Prevalence of secondary smoking and consumption of smokeless tobacco is also high in Bangladesh. ${ }^{8}$

Two third of the patients were hypertensive with $69 \%$ of them taking some form of antihypertensive drugs. In BRAVE study $24 \%$ of patients were hypertensive, but in other studies it was $46 \%$ $57 \%$. Inclusion of more young patients in BRAVE study was probably reason of lower prevalence of HTN. Higher prevalence of HTN in our study was also due to taking $80 \mathrm{~mm}$ of $\mathrm{Hg}$ as the cut of value for HTN, instead of $90 \mathrm{~mm}$ of $\mathrm{Hg}$. About $18 \%$ of the adult population is hypertensive. And one third of the general population has never measured their blood pressure. ${ }^{8}$

Most of our patients were of normal BMI and only $28.9 \%$ were overweight. None of the patients were obese. This is consistent with other studies in Bangladesh. ${ }^{11}$ This rate is much higher than the rate in general population of the country, which is $18 \%{ }^{8}$

$44 \%$ patients were diabetic. The study conducted in Rajshahi medical college revealed similar findings. ${ }^{6}$ But BRAVE study showed $22 \%$ patients with MI had DM. ${ }^{7}$ Among the study population $62 \%$ had anterior MI and $34.7 \%$ had inferior MI. DM, dyslipidaemia and family history of premature CVD were more common in patients with anterior MI and HTN was more common in inferior MI.

Though dyslipidaemia has got different definitions and indications of treatment depending on comorbid conditions. We evaluated the patients' lipid profile considering a generalized level. The prevalence lipid disorder is very high in this study population. This is consistent with studies in general population, $41 \%$ of the urban people and $30 \%$ of the rural population suffer some form dyslipidaemia. ${ }^{17}$ Genetic make-up of the population, dietary habit and life style may be responsible for this. With more urbanization and economic development, dietary habit of the people is in a state of transition. Liberal use of saturated fats and trans fats, deep frying, reuse of cooking oil, and overcooking leading to destruction of folates may all contribute to dyslipidemia in this population. ${ }^{18}$

We also evaluated prevalence of renal failure among the patients with MI. 25 (17.4\%) patients had renal impairment. Renal failure and IHD have got similar risk factors and $60 \%$ of patients with renal failure ultimately die of cardiovascular diseases.

Only $6 \%$ patients had no major risk factors. $57 \%$ patients had three or more major risk factors for cardiovascular diseases. Similar results are also revealed in other studies conducted in different centers of the country. ${ }^{6,}{ }^{11}$ In Bangladesh, 98\% adult people has got at least one risk factor for noncommunicable diseases and $28 \%$ people has got three or more risk factors. The increased rate of cardiovascular risk factors in this population is probably due to lack education and lack of awareness \& health care facilities \& appropriate treatment strategy. In low income countries, cardiovascular disease is more prevalent among people with lower level of education. ${ }^{19}$ This trend 
of higher prevalence of cardiovascular risk factors is also present in Bangladeshi population who reside in UK and they have $112 \%$ higher mortality rate from coronary artery disease and $220 \%$ higher mortality from stroke in comparison European population. ${ }^{20}$ This is probably one of the reason why south Asian people suffer from MI at an earlier age than that of other population. ${ }^{21}$ This is also evident in the AHA scientific statement on Atherosclerotic Cardiovascular Disease in South Asians in the United States: Epidemiology, Risk Factors, and Treatments. ${ }^{22}$ Similar type high prevalence is also evident among the patients with acute coronary syndrome in Nepal. ${ }^{23}$

Less proficient in knowledge about CVD and a poor understanding of diet and exercise in reducing CVD \& the association of tobacco smoking with CVD mortality was among the Bangladeshi population by a survey in Dhaka city specially in poor, uneducated population from low socioeconomic condition. ${ }^{24}$ This is probably also applicable in this population in the suburb near Dhaka city is the reason high prevalence of cardiovascular risk factors.

We could also evaluate the other cardiovascular risk factors like- lack of physical activity, smokeless tobacco, secondary smoking, dietary habit, use of oral contraceptives, air pollution, arsenicosis and biochemical parameters like homocysteine, uric acid level \& apolipoprotiens. We recommend this should done in a nationwide survey.

\section{Conclusion:}

Patients with MI in this secondary level hospital of a district town in Bangladesh are different from the patient population of the tertiary centers of the capital city. The prevalence of cardiovascular risk factors like HTN, dyslipidaemia and DM is more in this population, but the prevalence of smoking was less. A survey of these risk factors in the general population of this geographic area should be done to estimate their prevalence and to take measures to control them and thus to prevent cardiovascular diseases. This is also necessary in planning a national strategy to control cardiovascular diseases.

\section{Conflict of Interest - None.}

\section{References:}

1. Alwan A, Armstrong T, Bettcher D, Branca F, Chisholm D, Ezzati M, et al. Global status report on noncommunicable diseases 2010. Available at https:/ /www.who.int/nmh/publications/ncd_report2010/en/. Accessed on 2nd Jan 2020.

2. Karar ZA, Alam N, Streatfield PK, Epidemiological transition in rural Bangladesh, 1986-2006. Glob Health Action 2009 Jun 19; 2. doi: 10.3402/gha.v2i0.1904.

3. Jose PO, Frank AT, Kapphahn KI, Goldstein BA, Eggleston K, Hastings KG, Cullen MR, Palaniappan LP. Cardiovascular disease mortality in Asian Americans. J Am Coll Cardiol 2014;64:2486-2494. doi: 10.1016/j.jacc.2014.08.048

4. Joshi P, Islam S, Pais P, Reddy S, Dorairaj P, Kazmi K, et al. Risk factors for early myocardial infarction in South Asians compared with individuals in other countries. JAMA 2007;297(3):286-94.

5. Karim MA, Majumder AAS, Islam KQ, Alam MB, Paul ML, Islam MS, et al. BMC Cardiovascular Disorders (2015) 15:73 DOI 10.1186/s12872-015-0069-2

6. Rahsid A, Islam MM, Islam MR. Selected Risk Factors for Myocardial Infarction among the Patients Admitted in Rajshahi Medical College Hospital. TAJ 2005; 18(1): 37-42.

7. Chowdhury R, Alam DS, Fakir II, Adnan SD, Naheed A, Tasmin I, et al. The Bangladesh Risk of Acute Vascular Events (BRAVE) Study: objectives and design. Eur J Epidemiol 2015; 30:577-587. DOI 10.1007/s10654015-0037-2

8. Rahman MM, Chowdhury MAJ, Ahasan HAMN, Rahman MR, Hasan MM, Karim SR, et al. NonCommunicable Disease Risk Factor Survey Bangladesh 2010.available-

9. American Diabetes Association. Classification and Diagnosis of Diabetes: Standards of Medical Care in Diabetes-2018. Diabetes Care 2018 Jan; 41(Supplement 1): S13-S27. doi.org/10.2337/dc18-S002.

10. Hicks KA, Tcheng JE, Bozkurt B, Chaitman BR, Cutlip DE, Farb A, et al. 2014 ACC/AHA Key Data Elements and Definitions for Cardiovascular Endpoint Events in Clinical Trials. Circulation 2015; 132 (4): 302-361. doi.org/ 10.1161/CIR.0000000000000156

11. Kabiruzzaman M, Ali MA, Islam MN. Risk factor profile of first MI admitted in a tertiary care cardiac hospital in Bangladesh. JHNFB 2012;1: 2-7.

12. Amanullah M, Thapa LB, Farooque GM, et al. A profile of 51 cases of acute myocardial infarctionamongst young Bangladeshi. In: Proceedings of Bangladesh-Japan joint conference on Cardiovascular Disease, Dhaka 1984;JICA, 118-121.

13. Zaman MA, Majumder AAS, Ahmed R. Study of coronary care unit patients in Dhaka Medical College Hospital. Bangladesh J Med 1992;3: 4-6. 
14. Jalaluddin M, Malik A. A study of relation of smoking with myocardial infarction in 100 cases. Bangladesh Heart J 1986; 1:32-35.

15. Malik A, Islam MN, Zafar A, et al. Clinical patterns of ischaemic heart diseases and its association with some known risk factors. Bangladesh Heart J 1987; 2:1-9.

16. Ullah M, Saha S. Modifiable Cardiovascular Risk Factors in Hypertensive Patients. Cardiovasc J 2018; 11(1), 1016. DOI.org/10.3329/cardio.v11i1.38236

17. Fatema K, Zwar N Arnold, Milton A Hasnat, Ali L, Rahman B. Prevalence of risk factors for cardiovascular diseases in Bangladesh: A systematic review and metaanalysis. PLoS One 2016; 11 (8): 0160180-1-0160180-14.

18. Enas EA, Senthilkumar A, Chennikkara H, et al. Prudent diet and preventive nutrition from pediatrics to geriatrics: current knowledge and practical recommendations. Indian Heart J. 2003; 55: 310e338.

19. Rosengren A, Smyth A, Rangarajan S, Ramasundarahettige C, Bangdiwala SI, AlHabib KF, et al. Socioeconomic status and risk of cardiovascular disease in 20 low-income, middle-income, and highincome countries: the Prospective Urban Rural Epidemiologic (PURE) study. Lancet Glob Health 2019; 7: e748-60.
20. Joshi P, Islam S, Pais P, et al. Risk factors for early myocardial infarction in south Asians compared with individuals in other countries. JAMA 2007;297:286e294.

21. Joshi P, Islam S, Pais P, Reddy S, Dorairaj P, Kazmi K, et al. Risk Factors for Early Myocardial Infarction in South Asians Compared With Individuals in Other Countries. JAMA 2007;297:286-294.

22. Volgman AS, Palaniappan LS, Aggarwal NT, Gupta M, Khandelwal A, Krishnan AV, et al. Atherosclerotic Cardiovascular Disease in South Asians in the United States: Epidemiology, Risk Factors, and Treatments- A Scientific Statement From the American Heart Association. Circulation 2018; 138: e1-e34. DOI: 10.1161/CIR.0000000000000580

23. Khatri P, Simkhada R. Study on conventional risk factors in acute coronary syndrome. Journal of Universal College of Medical Sciences 2015; 3(2): 1-4.

24. Mirza AS, Aslam S, Perrin K, Curtis T, Stenback J, Gipson J, et al. Knowledge, attitudes and practices among patients with coronary artery disease in Dhaka, Bangladesh. Int J Community Med Public Health 2016 Oct;3(10):2740-2748. DOI: $\quad 10.18203 / 2394$ 6040.ijcmph20163355. 